\title{
Common genes underlying asthma and COPD? Genome-wide analysis on the Dutch hypothesis
}

\author{
Joanna Smolonska ${ }^{1,2,3}$, Gerard H. Koppelman ${ }^{3,4}$, Cisca Wijmenga', Judith M. Vonk ${ }^{2,3}$, Pieter Zanen 5 , \\ Marcel Bruinenberg', Ivan Curjuric ${ }^{6,7}$, Medea Imboden ${ }^{6,7}$, Gian-Andri Thun ${ }^{6,7}$, Lude Franke ${ }^{1}$, \\ Nicole M. Probst-Hensch ${ }^{6,7}$, Peter Nürnberg ${ }^{8}$, Roland A. Riemersma ${ }^{3,9}$, Constant P. van Schayck ${ }^{10}$ \\ Daan W. Loth ${ }^{11,12}$, Guy G. Brusselle ${ }^{11,13,14}$, Bruno H. Stricker ${ }^{11,12,15}$, Albert Hofman ${ }^{11,15}$, André G. Uitterlinden ${ }^{15,16}$, \\ Lies Lahousse ${ }^{11,13}$. Stephanie J. London ${ }^{17}$. Laura R. Loehr ${ }^{18}$. Ani Manichaikul ${ }^{19,20}$, R. Graham Barr ${ }^{21}$, \\ Kathleen M. Donohue ${ }^{21}$, Stephen S. Rich ${ }^{19}$, Peter Pare ${ }^{22}$, Yohan Bossé23, Ke Hao ${ }^{24}$, Maarten van den Berge ${ }^{3,9}$, \\ Harry J.M. Groen ${ }^{9}$, Jan-Willem J. Lammers ${ }^{25}$, Willem Mali ${ }^{26}$, H. Marike Boezen ${ }^{2,3}$ and Dirkje S. Postma ${ }^{3,9}$
}

\begin{abstract}
Affiliations: 'Dept of Genetics, University Medical Center Groningen, University of Groningen, Groningen, The Netherlands. ${ }^{2}$ Dept of Epidemiology, University Medical Center Groningen, University of Groningen, Groningen, The Netherlands. ${ }^{3}$ GRIAC Research Institute, Groningen University Medical Center, University of Groningen, Groningen, The Netherlands. 'Dept of Paediatric Pulmonology and Paediatric Allergology, Beatrix Children's Hospital, University Medical Center, University of Groningen, Groningen, The Netherlands. ${ }^{5}$ Dept of Pulmonology, University Medical Center Utrecht, Utrecht, The Netherlands. ${ }^{6}$ Dept of Epidemiology and Public Health, Swiss Tropical and Public Health Institute, Basel, Switzerland. ${ }^{7}$ University of Basel, Basel, Switzerland. ${ }^{8}$ Cologne Center for Genomics, University of Cologne, Cologne, Germany. ${ }^{9}$ Dept of Pulmonology, University Medical Center Groningen, University of Groningen, Groningen, The Netherlands. ${ }^{10}$ Dept of General Practice, University of Maastricht, Maastricht, The Netherlands. "11Dept of Epidemiology, Erasmus MC, Rotterdam, The Netherlands. ${ }^{12}$ Netherlands Healthcare Inspectorate, The Hague, The Netherlands. ${ }^{13}$ Dept of Respiratory Medicine, Ghent University Hospital, Ghent, Belgium. ${ }^{14}$ Dept of Respiratory Medicine, Erasmus MC, Rotterdam, The Netherlands. ${ }^{15}$ Netherlands Consortium for Healthy Aging (NCHA), Rotterdam, The Netherlands. ${ }^{16}$ Dept of Internal Medicine, Erasmus MC, Rotterdam, The Netherlands. ${ }^{17}$ Division of Intramural Research, National Institute of Environmental Health Sciences, National Institutes of Health, Dept of Health and Human Services, Research Triangle Park, NC, USA. ${ }^{18}$ University of North Carolina, Chapel Hill, NC, USA. ${ }^{19}$ Center for Public Health Genomics, University of Virginia, Charlottesville, VA, USA. ${ }^{20}$ Dept of Public Health Sciences, Division of Biostatistics and Epidemiology, University of Virginia, Charlottesville, VA, USA. ${ }^{21}$ Dept of Medicine, College of Physicians and Surgeons, Columbia University, New York, NY, USA. ${ }^{22}$ Respiratory Division, Dept of Medicine, University of British Columbia James Hogg Research Centre, St Paul's Hospital, Vancouver, BC, Canada. ${ }^{23}$ Institut Universitaire De Cardiologie Et De Pneumologie De Québec, Dept of Molecular Medicine, Laval University, Québec, QC, Canada. ${ }^{24}$ Dept of Genetics and Genomics Sciences, Mount Sinai School of Medicine, New York, NY, USA. ${ }^{25}$ Dept of Pulmonology, University Medical Center Utrecht, Utrecht, The Netherlands. ${ }^{26}$ Dept of Radiology, University Medical Center Utrecht, Utrecht, The Netherlands.
\end{abstract}

Correspondence: Dirkje S. Postma, University Medical Center Groningen, Groningen Research Institute for Asthma and COPD (GRIAC), Hanzeplein 1, Groningen, Netherlands. E-mail: d.s.postmadumcg.nl

ABSTRACT Asthma and chronic obstructive pulmonary disease (COPD) are thought to share a genetic background ("Dutch hypothesis").

We investigated whether asthma and COPD have common underlying genetic factors, performing genome-wide association studies for both asthma and COPD and combining the results in meta-analyses.

Three loci showed potential involvement in both diseases: chr2p24.3, chr5q23.1 and chr13q14.2, containing DDX1, COMMD10 (both participating in the nuclear factor (NF) $\kappa \beta$ pathway) and GNG5P5, respectively. Single nucleotide polymorphisms (SNPs) rs9534578 in GNG5P5 reached genome-wide significance after first replication phase $\left(\mathrm{p}=9.96 \times 10^{-9}\right)$. The second replication phase, in seven independent cohorts, provided no significant replication. Expression quantitative trait loci (eQTL) analysis in blood cells and lung tissue on the top 20 associated SNPs identified two SNPs in COMMD10 that influenced gene expression.

Inflammatory processes differ in asthma and COPD and are mediated by $\mathrm{NF}-\kappa \beta$, which could be driven by the same underlying genes, COMMD10 and DDX1. None of the SNPs reached genome-wide significance. Our eQTL studies support a functional role for two COMMD10 SNPs, since they influence gene expression in both blood cells and lung tissue. Our findings suggest that there is either no common genetic component in asthma and COPD or, alternatively, different environmental factors, e.g. lifestyle and occupation in different countries and continents, which may have obscured the genetic common contribution.

@ERSpublications

This article provides suggestive evidence, but not firm evidence that there is overlap in genetics of asthma and COPD http://ow.ly/we9yE 


\section{Introduction}

Asthma and chronic obstructive pulmonary disease (COPD) are two common respiratory diseases. Their estimated prevalence ranges from $\sim 1 \%$ to $18 \%$ in different countries [1-3]. Both diseases may lead to airway obstruction, which is reversible in asthma but not in COPD. However, the diagnosis cannot rely on reversibility as it can disappear with asthma progression, making both asthma and COPD harder to distinguish. The immune mechanisms underlying the two diseases are thought to be very different, but similarities in inflammatory processes have recently been reported in both disease entities [4]. Classically inflammation in asthma is represented by elevated numbers of CD4+ lymphocytes and eosinophils, while in COPD there are CD8+ lymphocytes, macrophages and neutrophils [5]. However, severe asthma can be accompanied by neutrophilia [6] and COPD exacerbation by eosinophilia [7].

Over 50 years ago, the so called "Dutch hypothesis" was formulated by ORIE et al. [8] stating that asthma and COPD are two features of one disease entity, referred to as chronic nonspecific lung disease (CNSLD). CNSLD was defined to result from the interplay of endogenous factors like genetic predisposition, and exogenous factors like viral infections, air pollution, tobacco smoking and allergen exposures. The timing of this interplay would then determine which clinical syndrome developed during a lifetime, i.e. asthma or COPD or features of both asthma and COPD.

So far this hypothesis has neither been confirmed nor refuted completely [9], but several common environmental exposures have been unequivocally identified as shared risk factors for both asthma and COPD, e.g. maternal smoking during pregnancy, air pollution and active smoking [10]. Genetic factors have been associated with either asthma or COPD using linkage [11-15], candidate gene [16-19] and genomewide association studies (GWAS) [20,21]. These studies elucidated genetic factors unique either to asthma or COPD, but in addition potentially shared genetic risk factors including TGFB1, TNFA, GSTP1, IL13 [22] and SERPINE2 [23]. ADAM33 has been linked to the presence of asthma [24], COPD and accelerated lungfunction decline in the general population and in asthma $[25,26]$, suggesting common underlying genetic factors for both onset and course of asthma and COPD. So far, hypothesis-free GWAS studies that aim to identify novel genes underlying both asthma and COPD in the same source population are lacking. The aim of our study was to identify shared genetic-risk factors for asthma and COPD using an unbiased GWAS approach. We first performed a GWAS on asthma and COPD separately using individuals from Dutch descent and subsequently combined these in a meta-analysis, followed by three replication studies.

\section{Methods \\ Study populations}

For the identification phase, subjects were recruited from the following asthma and COPD cohorts. 1) The Dutch Asthma GWAS (DAG) Study, a cohort screened for genetic studies and characterised by the presence of a doctor diagnosis for asthma and bronchial hyperresponsiveness [27]. 2) The Dutch-Belgian Randomised Lung Cancer Screening (NELSON) trial [28]: a population-based cohort screening for lung cancer that includes current or ex-smokers with at least 20 pack-years. To increase power of the COPD set, blood bank controls from Amsterdam and Utrecht (both the Netherlands) without clinical data except for age (range 18-65), were added.

The results of the GWAS were meta-analysed (meta-analysis 1). A meta-analysis is a method to combine results from different studies, with the aim of estimating a true effect size as opposed to a less-precise effect size derived in a single study. A weighted average of that common effect size is the output of a meta-analysis. The weighting is related to sample sizes within the individual studies.

For the first replication phase (meta-analysis 2) participants of the LifeLines cohort study (LifeLines 1) were studied. In the second replication phase (meta-analyses 3-9) the top 20 single nucleotide polymorphisms (SNPs) with the smallest p-value (most significant) were evaluated in participants of an independent sample of the LifeLines cohort study (LifeLines 2), the Swiss Cohort Study on Air pollution and Lung Diseases in Adults (SAPALDIA), the Rotterdam Study (RS)-I, -II, and -III, the Multi-Ethnic Study of Atherosclerosis (MESA), and Atherosclerosis Risk in Communities Study (ARIC) cohorts (for further information on these studies see the online supplementary material).

This article has supplementary material available from www.erj.ersjournals.com

Received: Jan 032014 | Accepted after revision: April 142014 | First published online: July 032014

Conflict of interest: Disclosures can be found alongside the online version of this article at www.erj.ersjournals.com

The content of this work is not subject to copyright. Design and branding are (CERS 2014. 
There were no overlapping subjects in any cohorts used. All participants signed informed consent and the studies were approved by institutional ethics committees. Detailed information and characteristics of the study populations are shown in the online supplementary material (table S1).

\section{Asthma and COPD phenotype definition}

In all of the cohorts asthma was defined as having a doctor diagnosis of asthma ever, or use of asthma medication (beta-agonists, steroids, anticholinergics, cromoglycate, montelukast, theophyllines), while ever having two or more of the following symptoms: wheeze without a cold, an attack of breathlessness while resting, waking up with an attack of breathlessness. Controls were defined as not having asthma.

In all cohorts, COPD was defined as a pre-bronchodilator forced expiratory volume in $1 \mathrm{~s}(\mathrm{FEV} 1) /$ forced vital capacity (FVC) $<0.7$ (asthma cases were excluded), and controls (except for blood bank controls) were defined as having an FEV1/FVC $>0.7$ and $\mathrm{FEV}_{1}>90 \%$ pred.

\section{Genotyping, quality control and imputation}

All cohorts were genotyped with Illumina arrays with different SNP content. Genotypes were called and standard quality control was performed (online supplementary material).

\section{Study design and statistical analyses}

The analytic workflow is shown in figure 1. Genome-wide associations on asthma (2004043 SNPs) and COPD (1 872289 SNPs) were performed using Chi-squared test using a genetic additive model (0, 1, and 2).

The results were combined in a meta-analysis using 1811026 SNPs shared between the asthma and COPD datasets (meta-analysis 1). 2048 SNPs showing $\mathrm{p}<0.001$ were selected for in silico replication in a second set of asthma and COPD case-control groups derived from the LifeLines cohort (LifeLines 1). These markers were analysed with Chi-squared tests and then combined in a second directional meta-analysis (metaanalysis 2). The top 20 SNPs with $\mathrm{p} \leqslant 0.001$ from meta-analysis 2 were investigated in the second replication phase consisting of seven meta-analyses in LifeLines 2, SAPALDIA, RS-I, RS-II, RS-III, MESA, and ARIC (for cohort description see online supplementary material).

In the meta-analyses (apart from LifeLines 2) genetic associations with asthma and COPD were tested using logistic regression. Models were controlled for pack-years smoking, study area and principal components capturing inter-European population structure. Results were then combined using the Fisher's method. SNPs with $\mathrm{p}<0.05$ in meta-analysis 2 are shown in table S4.

\section{Expression quantitative trait loci mapping in blood and lung tissue}

Expression quantitative trait loci (eQTL) mapping in blood was performed as described previously by FEHRMANN et al. [29]. In brief, each probe on the expression chip was mapped and correlated with SNPs in the vicinity of $250 \mathrm{~kb}$. Principal component analysis was applied to the data prior to the analysis to ensure that signals detected as eQTLs were not due to batch effects. Analysis involved nonparametric Spearman's rank correlation test. Because two different expression chips were used, when probes were present on both, the final result came from meta-analysis. False discovery rate was applied to account for multiple testing.

eQTL-mapping in lung tissue was performed as described previously in three independent data sets in a collaboration between University of Groningen (Groningen, The Netherlands), Laval University (Quebec City, Canada) and British Columbia (Vancouver, Canada) [30]. The lung specimens were obtained from patients undergoing lung resection surgery at the three participating sites. Whole-genome gene expression and genotyping data were obtained from these specimens. Gene expression profiling was performed using the GEO platform GPL10379 custom array (Affymetrix, Santa Clara, CA, USA) testing 51627 noncontrol probe sets and normalised using robust multi-array average (RMA) [31]. Genotyping was performed using the Human1M-Duo BeadChip array (Illumina, San Diego, CA, USA). Following standard microarray and genotyping quality controls, 1111 patients were available for eQTL analyses. Cis- and trans-acting eQTLs were calculated as previously performed [32].

\section{Network analysis}

Gene network was constructed using GeneMANIA (University of Toronto, Toronto, Canada) [33]. The gene set resulting from this approach was investigated with GATHER [34] to identify enriched pathways. Further details are provided in the online supplementary material.

\section{Results}

GWAS and meta-analyses

GWAS were performed on both asthma (921 cases and 3246 controls) and COPD (1030 cases and 1808 controls). The genomic inflation factors $(\lambda)$ were 1.01 for both asthma and COPD, indicating no population 


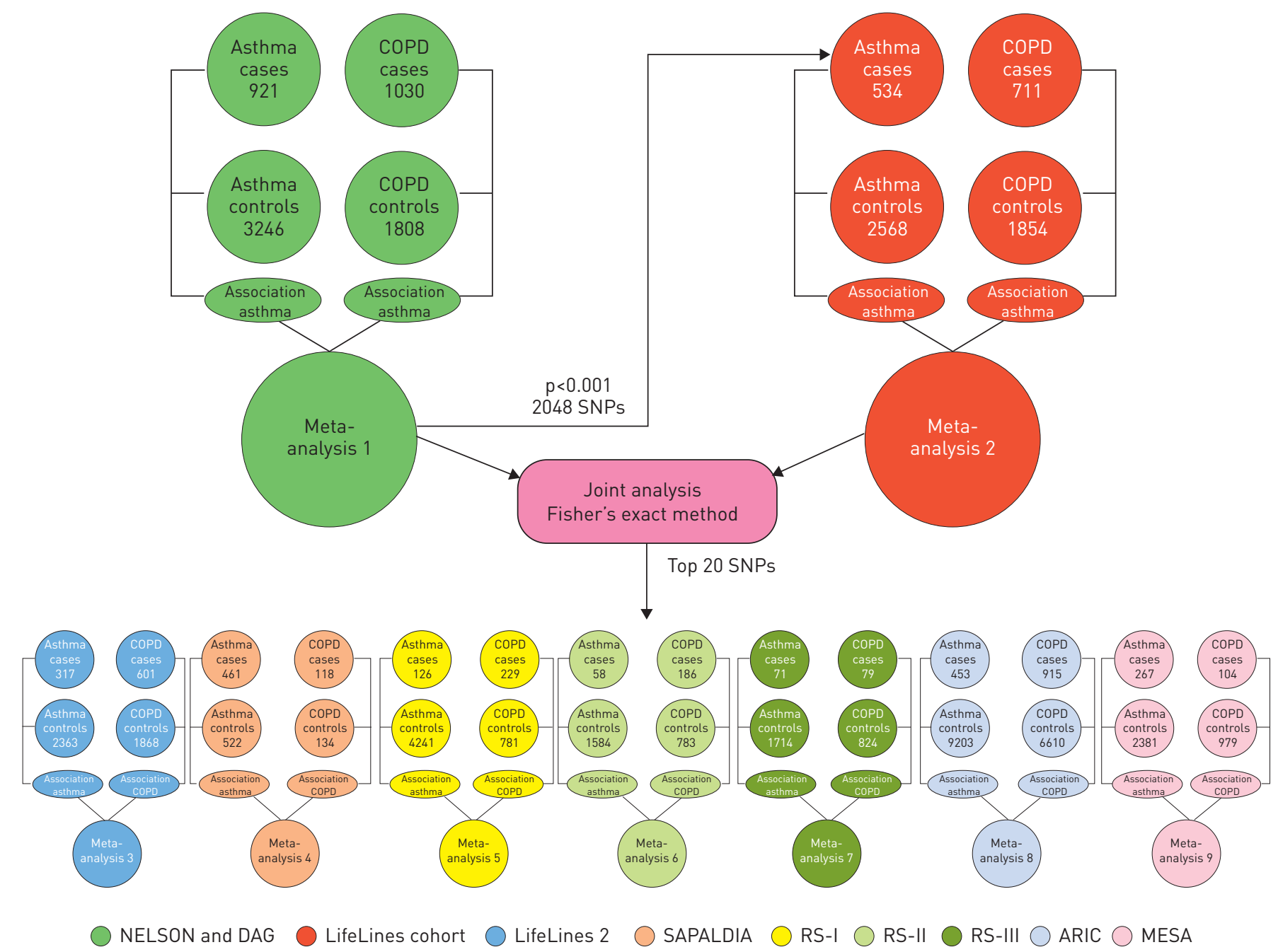

FIGURE 1 Analytic workflow for the current study. COPD: chronic obstructive pulmonary disease; SNPs: single nucleotide polymorphism; meta-analysis 1: first meta-analysis; meta-analysis 2: first replication phase; meta-analysis 3-9: second replication phase; NELSON: The Dutch-Belgian Randomised Lung Cancer Screening Trial; DAG: The Dutch Asthma Genome-wide association studies; SAPALDIA: Swiss Cohort Study on Air pollution and Lung Diseases in Adults; RS: Rotterdam Study; ARIC: Atherosclerosis Risk in Communities Study; MESA: Multi-Ethnic Study of Atherosclerosis.

stratification (fig. S1). Individual p-values and odds ratios (ORs) were combined in a directional metaanalysis using a fixed-effects model (meta-analysis 1, fig. 1). All 2048 SNPs with $\mathrm{p} \leqslant 0.001$ were selected for a first-replication phase analysis in asthma (534 cases and 2568 controls) and COPD (711 cases and 1854 controls) cohorts separately. Subsequently results were combined in a meta-analysis (meta-analysis 2, fig. 1).

20 SNPs replicated at $\mathrm{p}<0.001$ (table 2) in the combined meta-analysis 1 and meta-analysis 2, one SNP reached genome-wide significance.

19 of the 20 SNPs map to three genomic locations: 2p24.3, 5q23.1, and 13q14.2 (table S2).

The chromosome 2 p24.3 locus spans $\sim 380 \mathrm{~kb}$ and contains genes encoding functional units, like processed transcripts, pseudogenes and RNA genes (fig. 2). The nearest gene with a known function, DEAD-box polypeptide 1 (DDX1), is $\sim 139 \mathrm{~kb}$ away from the top associated 2p24.3 SNP rs1477253. The locus on chromosome 5 is $\sim 328 \mathrm{~kb}$ and contains a single gene: COMM domain containing 10 (COMMD10) (fig. 2). The locus on chromosome 13 spans $\sim 320 \mathrm{~kb}$ and only contains a pseudogene: guanine nucleotide binding protein (G protein), gamma 5 pseudogene 5 (GNG5P5) (fig. 2). SNP rs9534578 in GNG5P5 reached genomewide significance $\left(\mathrm{p}=9.96 \times 10^{-9}\right)$.

\section{Second replication phase of top 20 SNPs}

The top 20 markers from the combined analysis were further evaluated in an independent sample of the LifeLines cohort (LifeLines 2) and the SAPALDIA, RS-I, RS-II, RS-III, MESA and ARIC cohorts. Full details 
TABLE 1 Characteristics of the identification and replication cohorts

\begin{tabular}{|c|c|c|c|c|c|c|c|c|}
\hline Study & Phenotype & Subjects & Age years & Sex male & Current smoker & Never smoker & Ex-smoker & $\begin{array}{c}\text { Pack-years } \\
\text { median (IQR) }\end{array}$ \\
\hline DAG & $\begin{array}{l}\text { Asthma } \\
\text { Controls }\end{array}$ & $\begin{array}{c}920 \\
2777\end{array}$ & $\begin{array}{c}34 \pm 16 \\
55.4 \pm 9.9\end{array}$ & $\begin{array}{l}430(47) \\
991(36)\end{array}$ & $\begin{array}{l}147(16.0) \\
396(14)\end{array}$ & $\begin{array}{l}544(59.1) \\
1305 \text { (47) }\end{array}$ & $\begin{array}{l}226(24.6) \\
1076(39)\end{array}$ & $\begin{array}{l}7.9(2.1-17.3) \\
1.95(0-11.6)\end{array}$ \\
\hline NELSON & $\begin{array}{l}\text { COPD } \\
\text { Controls }\end{array}$ & $\begin{array}{c}1030 \\
844^{\circ}+964^{+}\end{array}$ & $\begin{array}{l}63.3 \pm 5.6 \\
59.1 \pm 5\end{array}$ & $\begin{array}{r}1030(100) \\
964(100)\end{array}$ & $\begin{array}{l}410(39.8) \\
621(64.4)\end{array}$ & $\begin{array}{l}0(0) \\
0(0)\end{array}$ & $\begin{array}{l}620(60.2) \\
343(35.6)\end{array}$ & $\begin{array}{l}38.7(29.7-49.5) \\
34.2(27.9-46.2)\end{array}$ \\
\hline LifeLines 1 & $\begin{array}{l}\text { Asthma } \\
\text { Controls } \\
\text { COPD } \\
\text { Controls }\end{array}$ & $\begin{array}{c}534 \\
2568 \\
711 \\
1854\end{array}$ & $\begin{array}{c}44.8 \pm 9.7 \\
43 \pm 9.4 \\
54 \pm 10.6 \\
43.2 \pm 8.6\end{array}$ & $\begin{array}{l}214(40) \\
1102(42.9) \\
369(52) \\
807(43.5)\end{array}$ & $\begin{array}{l}106(19.9) \\
266(10.4) \\
363(51.1) \\
805(43.4)\end{array}$ & $\begin{array}{c}293(54.9) \\
2010(78.8) \\
0(0) \\
0(0)\end{array}$ & $\begin{array}{r}135(25.3) \\
276(10.8) \\
348(48.9) \\
1049(56.6)\end{array}$ & $\begin{array}{c}10.8(4.9-20.5) \\
12.75(5.5-20.4) \\
16.8(8.5-26.7) \\
9(4-15)\end{array}$ \\
\hline LifeLines 2 & $\begin{array}{l}\text { Asthma } \\
\text { Controls } \\
\text { COPD } \\
\text { Controls }\end{array}$ & $\begin{array}{c}317 \\
2363 \\
601 \\
1868\end{array}$ & $\begin{array}{l}46.7 \pm 11.2 \\
48.5 \pm 11.6 \\
56.7 \pm 10.8 \\
49.6 \pm 10.9\end{array}$ & $\begin{array}{l}120(37.9) \\
885(37.5) \\
282(46.9) \\
784(42.0)\end{array}$ & $\begin{array}{l}41(12.9) \\
165(7.2) \\
231(38.4) \\
601(32.2)\end{array}$ & $\begin{array}{c}171(53.9) \\
1922(83.3) \\
0(0) \\
0(0)\end{array}$ & $\begin{array}{c}105(33.1) \\
220(9.5) \\
370(61.6) \\
1267(67.8)\end{array}$ & $\begin{array}{c}7.4(3-15.5) \\
12(5-20.5) \\
15.2(7-25.2) \\
8.6(4-16)\end{array}$ \\
\hline SAPALDIA 2 & $\begin{array}{l}\text { Asthma } \\
\text { Controls } \\
\text { COPD } \\
\text { Controls }\end{array}$ & $\begin{array}{l}461 \\
522 \\
118 \\
134\end{array}$ & $\begin{array}{l}49.0 \pm 11.8 \\
51.4 \pm 11.1 \\
58.3 \pm 10.0 \\
51.4 \pm 10.4\end{array}$ & $\begin{array}{r}212(46.0) \\
244(46.7) \\
67(56.8) \\
60(44.8)\end{array}$ & $\begin{array}{l}95(20.6) \\
95(18.2) \\
44(37.3) \\
30(22.4)\end{array}$ & $\begin{array}{r}215(46.6) \\
252(48.3) \\
49(41.5) \\
68(50.8)\end{array}$ & $\begin{array}{r}151(32.8) \\
175(33.5) \\
25(21.2) \\
36(26.9)\end{array}$ & $\begin{array}{c}16.3(4.9-32.9) \\
13.1(5.1-25.5) \\
37.0(15.4-52.7) \\
14.8(3.9-27.0)\end{array}$ \\
\hline RS-I & $\begin{array}{l}\text { Asthma } \\
\text { Controls } \\
\text { COPD } \\
\text { Controls }\end{array}$ & $\begin{array}{c}126 \\
4241 \\
229 \\
781\end{array}$ & $\begin{array}{l}65.8 \pm 7.8 \\
69.8 \pm 9.2 \\
79.8 \pm 4.9 \\
79.1 \pm 4.5\end{array}$ & $\begin{array}{r}33(26.2) \\
1499(35.3) \\
126(55) \\
306(39)\end{array}$ & $\begin{array}{r}24(19) \\
782(18) \\
51(22) \\
49(6)\end{array}$ & $\begin{array}{r}50(40) \\
1854(44) \\
36(16) \\
299(38)\end{array}$ & $\begin{array}{r}51(41) \\
1605(38) \\
142(62) \\
433(55)\end{array}$ & $\begin{array}{c}15.4(4.5-37.4) \\
20(7.5-37.5) \\
26(9.8-45) \\
16.8(5.7-36.0)\end{array}$ \\
\hline RS-II & $\begin{array}{l}\text { Asthma } \\
\text { Controls } \\
\text { COPD } \\
\text { Controls }\end{array}$ & $\begin{array}{c}58 \\
1584 \\
186 \\
783\end{array}$ & $\begin{array}{l}62.9 \pm 6.8 \\
64.7 \pm 8.0 \\
72.8 \pm 5.1 \\
72.1 \pm 4.9\end{array}$ & $\begin{array}{r}15(26) \\
712(45) \\
108(58) \\
327(42)\end{array}$ & $\begin{array}{r}7(12) \\
249(16) \\
48(26) \\
52(7)\end{array}$ & $\begin{array}{r}23(40) \\
526(33) \\
28(15) \\
317(41)\end{array}$ & $\begin{array}{r}28(48) \\
809(51) \\
110(59) \\
415(53)\end{array}$ & $\begin{array}{c}21.6(6-43.8) \\
14(3.6-31) \\
31.7(16.4-46.0) \\
13.9(3.7-28.0)\end{array}$ \\
\hline RS-III & $\begin{array}{l}\text { Asthma } \\
\text { Controls } \\
\text { COPD } \\
\text { Controls }\end{array}$ & $\begin{array}{c}71 \\
1714 \\
79 \\
824\end{array}$ & $\begin{array}{l}54.7 \pm 4.5 \\
55.8 \pm 5.6 \\
56.9 \pm 5.0 \\
56.5 \pm 5.5\end{array}$ & $\begin{array}{r}20(28) \\
764(45) \\
40(51) \\
353(43)\end{array}$ & $\begin{aligned} & 6(9) \\
& 356(21) \\
& 32(41) \\
& 137(17)\end{aligned}$ & $\begin{array}{r}27(38) \\
574(34) \\
19(24) \\
288(35)\end{array}$ & $\begin{array}{r}38(54) \\
784(46) \\
28(35) \\
399(48)\end{array}$ & $\begin{array}{c}15.5(1.2-25.7) \\
13.8(4.0-29.0) \\
28.9(16.2-44.7) \\
12.5(3.8-26.6)\end{array}$ \\
\hline ARIC & $\begin{array}{l}\text { Asthma } \\
\text { Controls } \\
\text { COPD } \\
\text { Controls }\end{array}$ & $\begin{array}{c}453 \\
9203 \\
915 \\
6610\end{array}$ & $\begin{array}{l}54.3 \pm 5.8 \\
54.8 \pm 5.7 \\
55.6 \pm 5.57 \\
54.1 \pm 5.67\end{array}$ & $\begin{array}{r}226(50) \\
4318(47) \\
506(55) \\
3042(46)\end{array}$ & $\begin{array}{r}107(23.62) \\
2268(24.64) \\
522(57.1) \\
1120(16.9)\end{array}$ & $\begin{array}{r}181(39.96) \\
3691(40.11) \\
93(10.2) \\
3096(46.8)\end{array}$ & $\begin{array}{c}165(36.42) \\
3239(35.20) \\
300(32.8) \\
2394(36.2)\end{array}$ & $\begin{array}{c}29.6(14.1-45.0) \\
26.0(12-40) \\
39(29-54) \\
20.3(9-34)\end{array}$ \\
\hline MESA & $\begin{array}{l}\text { Asthma } \\
\text { Controls } \\
\text { COPD } \\
\text { Controls }\end{array}$ & $\begin{array}{c}267 \\
2381 \\
104 \\
979\end{array}$ & $\begin{array}{l}61.1 \pm 9.6 \\
63.0 \pm 10.2 \\
67.1 \pm 8.9 \\
66.0 \pm 10.0\end{array}$ & $\begin{array}{r}119(45) \\
1149(48) \\
51(49) \\
467(48)\end{array}$ & $\begin{array}{r}29(11) \\
263(11) \\
19(18) \\
55(6)\end{array}$ & $\begin{array}{r}112(58) \\
1061(55) \\
15(14) \\
446(46)\end{array}$ & $\begin{array}{r}124(47) \\
1053(44) \\
70(67) \\
478(49)\end{array}$ & $\begin{array}{c}20(6-41.3) \\
19(6.6-37.8) \\
37(22-64) \\
17.3(7-36)\end{array}$ \\
\hline
\end{tabular}

Data are presented as mean \pm SD or $n(\%)$ unless otherwise stated. IQR: interquartile range; DAG: the Dutch Asthma Genome-wide association studies: NELSON: The Dutch-Belgian Randomised Lung Cancer Screening Trial; SAPALDIA: Swiss Cohort Study on Air pollution and Lung Diseases in Adults; ARIC: Atherosclerosis Risk in Communities Study; MESA: Multi-Ethnic Study of Atherosclerosis. " : calculated in ever smokers; ": blood bank controls, no demographic data; ${ }^{+}$: characteristics in this line for $n=964$.

of subject numbers are given in table 1 . None of the SNPs replicated at a nominal p-value $<0.05$. The metaanalysis of all cohorts together did not result in GWSA (table 2 and fig. 3).

SNPs in the DDX1 and COMMD10 loci were associated with both asthma and COPD (table S3). The metaanalysis results of the GNG5P5 locus were driven by the association with the COPD phenotype, since none of the GNG5P5 SNPs were significantly associated with the asthma phenotype.

eQTL analysis of top 20 SNPs

Three of the top 20 SNPs from the combined analysis showed a cis-eQTL effect, when correlating the genotypes with gene expression levels in 1469 peripheral blood mononuclear cell samples with both GWAS and genome-wide gene expression data available [29]. The three SNPs were located in COMMD10. Figure 4 shows that the risk guanine $(\mathrm{G})$ allele and SNP rs10043228 thymine (T) is in perfect linkage disequilibrium $\left(\mathrm{r}^{2}=1\right)$ with rs10036292, increased COMMD10 expression levels in blood mononuclear cells, with similar findings to those found in lung tissue.

\section{Network analysis}

The genes found were investigated with GeneMANIA, which does not support pseudogenes. Hence we queried only COMMD10 and DDX1. This gene enrichment approach resulted in a set of genes, two genes ( RAD50 and MRE11A) being involved in regulation of mitotic recombination (Bayes factor $11, \mathrm{p}<0.0001$ ) and telomere maintenance (Bayes factor $6, \mathrm{p}<0.0001$ ), possibly implicating COPD as a disease of rapidly aging lungs [35]. Another gene involved in telomere maintenance (BICD1) was previously reported in emphysema [36]. 


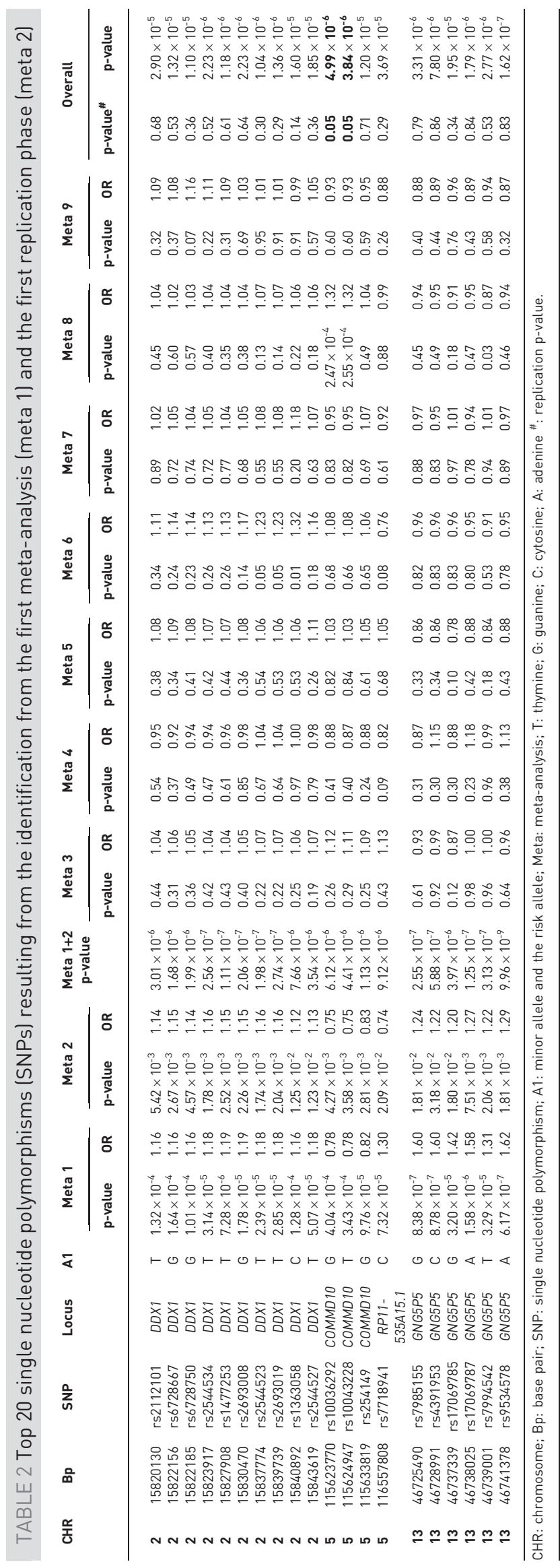



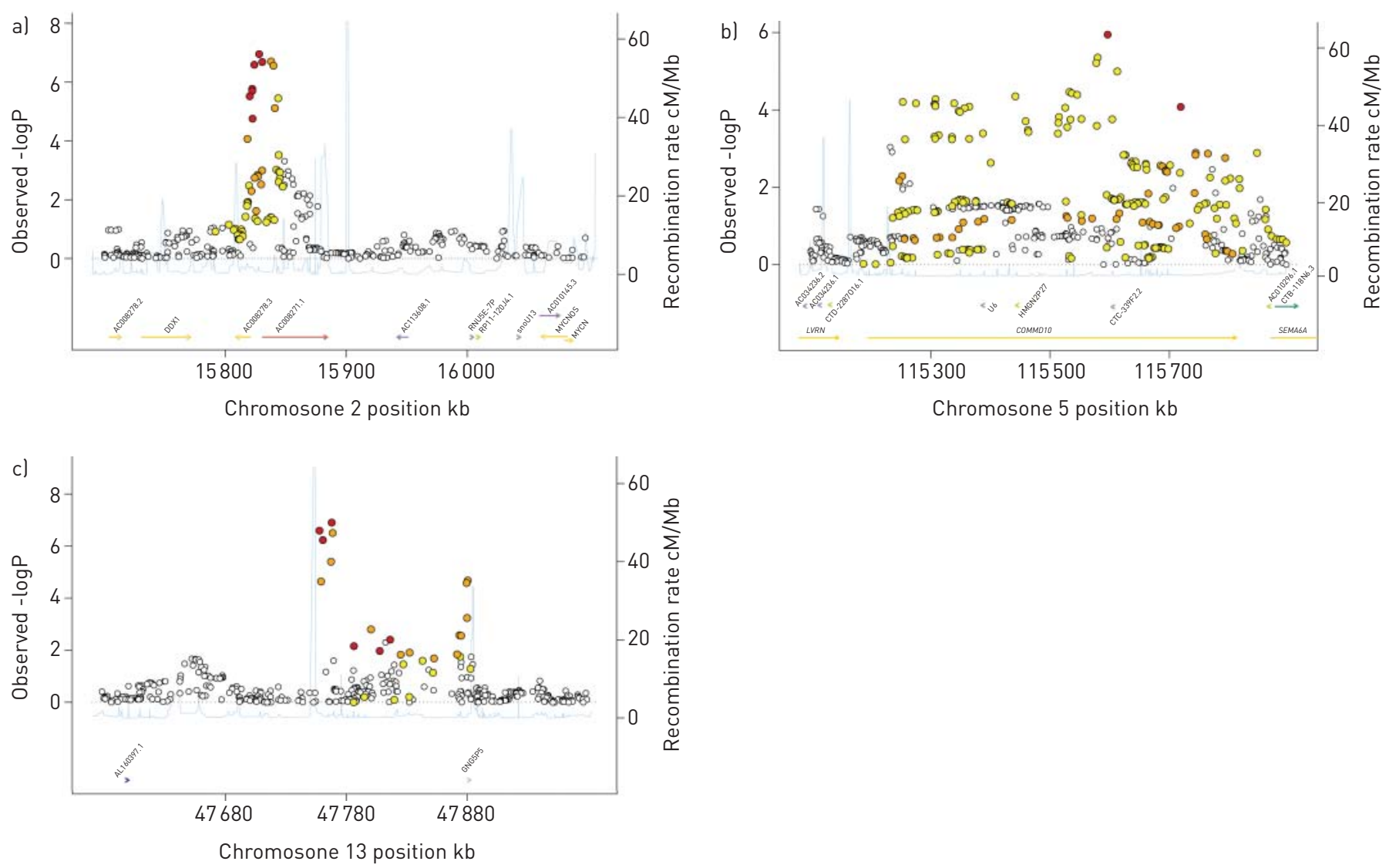

FIGURE 2 Regional association plots for loci a) DDX1, b) COMMD10 and c) GNG5P5. The plots were generated using R and regional association plot script from the BROAD institute (Cambridge, MA, USA).

Moreover, products of DDX1 and COMMD10 interact with nuclear factor (NF) $\kappa \beta 2$. COMMD10 has a direct interaction, while DDX1 interacts with RELA and RELB, known to interact directly with NF- $\kappa \beta 2$ and to function in the same pathway (fig. 5).

\section{Discussion}

This is the first investigation of shared genetics for asthma and COPD in a hypothesis-free manner using a genome-wide screening in asthma and COPD in large population-based cohorts. We report three novel loci

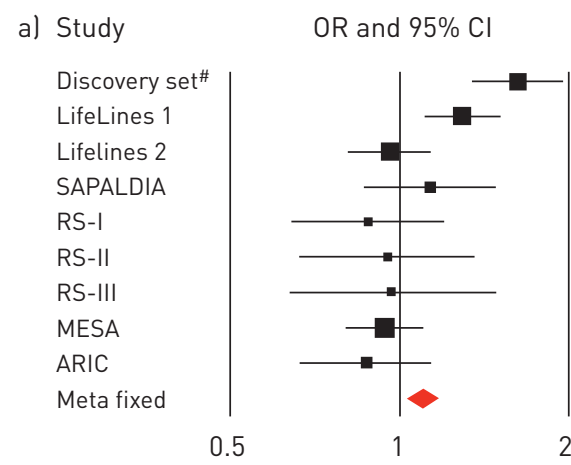

b) Study

\begin{tabular}{l|} 
Discovery set \\
LifeLines 1 \\
Lifelines 2 \\
SAPALDIA \\
RS-I \\
RS-II \\
RS-III \\
MESA \\
ARIC \\
Meta fixed
\end{tabular}

OR and $95 \% \mathrm{Cl}$

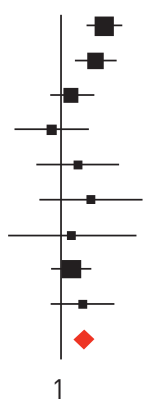

c) Study

\begin{tabular}{l|} 
Discovery set" \\
LifeLines 1 \\
Lifelines 2 \\
SAPALDIA \\
RS-I \\
RS-II \\
RS-III \\
MESA \\
ARIC \\
Meta fixed
\end{tabular}

OR and $95 \% \mathrm{Cl}$

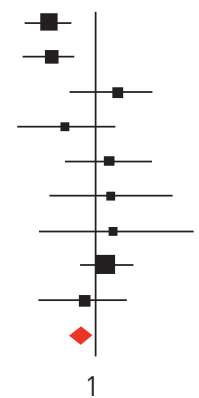

FIGURE 3 Forest plots of the three top single nucleotide polymorphisms (SNP) in the meta-analysis of the asthma and chronic obstructive pulmonary disease cohorts. a) SNP rs9534578 in GNG5P5. b) SNP rs1477253 in DDX1. c) SNP rs254149 in COMMD10. SAPALDIA: Swiss Cohort Study on Air pollution and Lung Diseases in Adults; RS: Rotterdam Study; MESA: Multi-Ethnic Study of Atherosclerosis: ARIC: Atherosclerosis Risk in Communities Study; Meta fixed: meta analysis with fixed effect. "\#: includes the Dutch-Belgian Randomised Lung Cancer Screening (NELSON) trial and the Dutch Asthma Genome-wide association studies (DAG). 

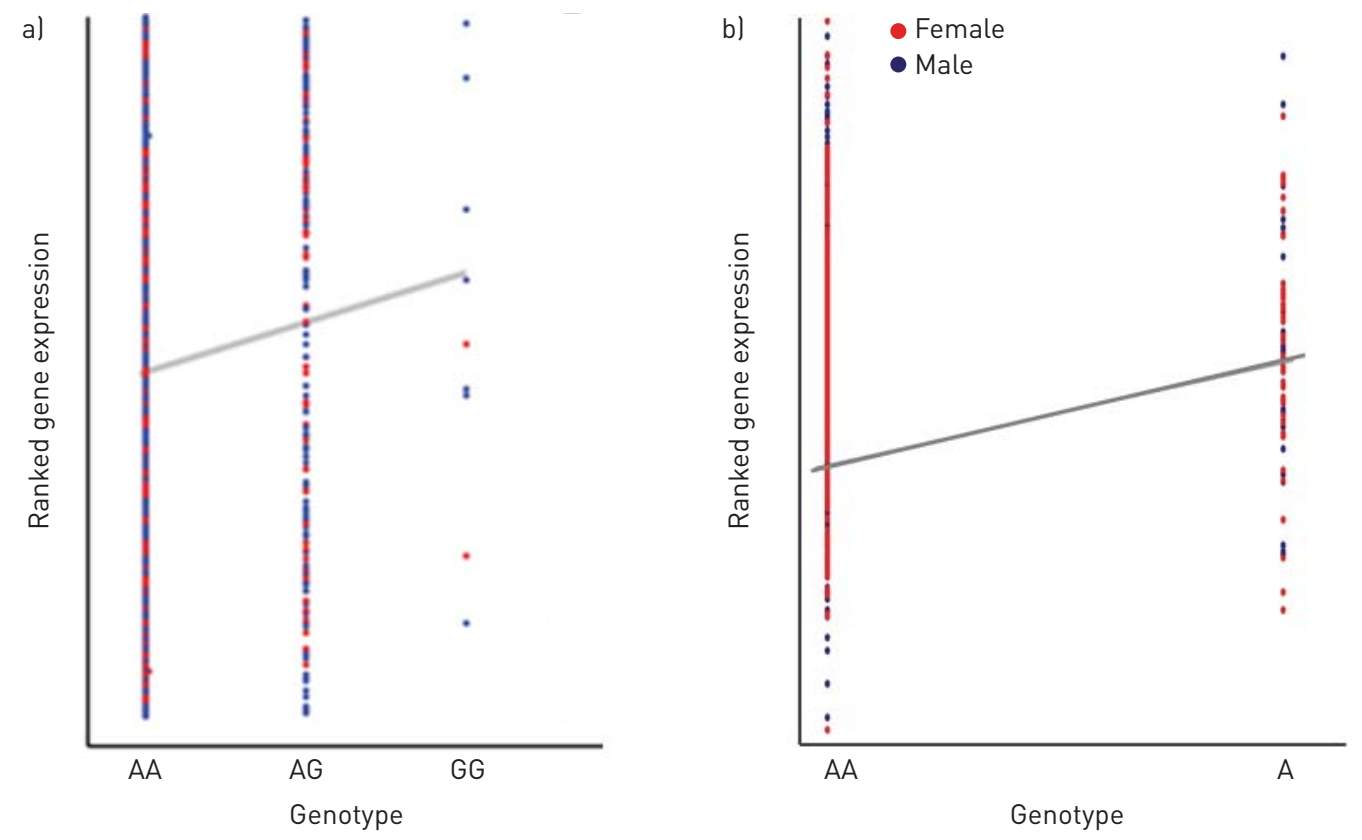

FIGURE 4 Expression quantitative trait loci (eQTL) identified for COMMD10 single nucleotide polymorphisms (SNPs) rs 10036292 in a) blood $\left(\mathrm{p}=3.68 \times 10^{-4}\right)$ and $\mathrm{b}$ ) lung tissue (meta-analysis $\left.\mathrm{p}=5.24 \times 10^{-9}\right)$. Order on $\mathrm{x}$-axis is from nonrisk homozygote to heterozygote and risk homozygote. Note in the lung tissue dataset, the risk homozygotes were not present.

as potentially shared genetic factors between asthma and COPD, none reaching genome-wide significance in the discovery sample or seven replication cohorts. None of these three loci were previously reported to be associated with either asthma or COPD. However, DDX1 locus was reported in a recently published metaanalysis of lung function [37], a p-value of $9 \times 10^{-6}$. The T allele of rs 2544527 in DDX was associated with a reduced lung function and in our study with a risk for both asthma and COPD.

The shared 5q23.1 risk locus contains the COMMD10 gene. COMMD10 is a member of COMM domain containing proteins [38] with a largely unknown function. COMMD10 has been shown to form a complex with COMMD1, another member of this family of proteins, which regulates copper metabolism and sodium uptake and inhibits NF- $\kappa \beta$ activation [39]. Copper and sodium levels are inversely regulated, i.e. when copper levels increase, sodium import in cells is inhibited and vice versa. Both ion levels can be regulated by COMMD1, with sodium control mediated through epithelial sodium channels (ENaCs) that are abundantly present in lung epithelial cells [40]. Sodium is crucial for maintaining a fluidic layer in the alveolar part of the lungs and ENaCs play a crucial role in this process [41]. It is tempting to speculate that COMMD10 is involved in this maintenance either through interaction with COMMD1, or independently by displaying similar functions as COMMD1. Also, its function in inhibition of NF- $\kappa \beta$ activation could play a role in regulating inflammatory processes in airways diseases. Our eQTL studies support a functional role of COMMD10, since we established that two SNPs in the COMMD10 region influence expression of this gene in both blood cells and lung tissue.

The 13q14.2 locus contains the guanine nucleotide binding protein (G protein) (GNG5P5). PoLISENO et al. [42] recently showed that pseudogenes can have a pronounced role in regulation of their putative transcripts by competing in noncoding RNA binding. It needs to be tested whether GNG5P5 can affect GNG5 levels, but it is interesting to note that the pseudogene is processed and has a transcript (ENST00000420444). The biological consequence of a change in GNG5 levels in relation to asthma and COPD pathology is unclear but it is well established that $\mathrm{G}$ proteins play a crucial role in signal transduction from cell surface to its interior. It is also known that G-protein coupled receptors (GPCRs) are involved in asthma and more generally are a target of many of the currently used asthma drugs [43].

A third locus on 2p24.3 is bordered by the DDX1 gene, encoding DEAD-box protein 1, RNA helicase I, and the MYCN genes whereas the locus itself contains nonprotein-coding genes including lincRNAs, ncRNAs, pseudogenes, processed transcripts and one newly discovered, protein-coding gene. Theoretically, any of these could be involved in asthma and COPD, hindering interpretation of our findings. However, the regional association plot (fig. 2) shows that the signal is mostly confined to AC008278.3 and AC008271.1. 


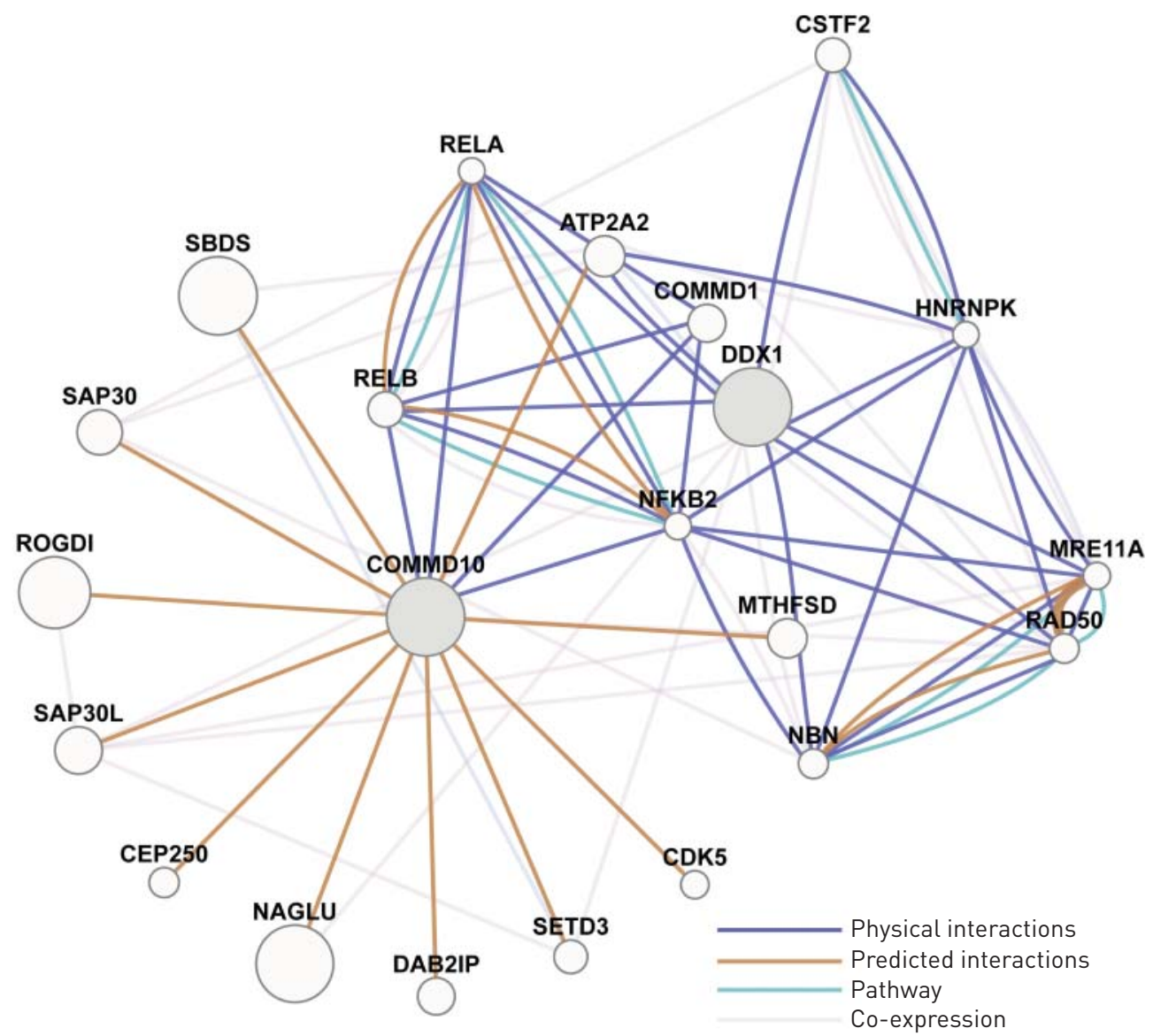

FIGURE 5 Gene enrichment plot using DDX1 and COMMD10 genes as a query. CSTF2: cleavage stimulation factor, 3' pre-RNA, subunit 2, 64kDa; HNRNPK: heterogeneous nuclear ribonucleoprotein K; MRE11A: MRE11 meiotic recombination 11 homolog A (Saccharomyces cerevisiae); RAD50: RAD50 homolog (S. cerevisiae); NBN: nibrin; MTHFSD: methenyltetrahydrofolate synthetase domain containing; NFKB2: nuclear factor of kappa light polypeptide gene enhancer in B-cells 2 (p49/p100); CDK5: cyclin-dependent kinase 5; SETD3: SET domain containing 3; DAB2IP: DAB2 interacting protein; NAGLU: N-acetylglucosaminidase, alpha; CEP250: centrosomal protein 250kDa; SAP30L: SAP30-like; ROGDI: rogdi homolog (Drosophila); SAP30: Sin3A-associated protein, 30kDa; SBDS: Shwachman-BodianDiamond syndrome; COMMD1: copper metabolism (Murr1) domain containing 1; RELB: v-rel reticuloendotheliosis viral oncogene homolog B; RELA:v-rel reticuloendotheliosis viral oncogene homolog A (avian); ATP2A2: ATPase, Ca++ transporting, cardiac muscle, slow twitch 2; COMMD10: COMM domain containing 10; DDX1: DEAD (Asp-Glu-AlaAsp) box polypeptide 1 .

Further refinement of the region and functional assessment of the associated variants could help to potentially pin-point the actual causal gene. DDX1 is a plausible candidate for both asthma and COPD since it interacts with RELA, one of NF- $\kappa \beta$ subunits, upon which it acts as a co-activator of NF- $\kappa \beta$ mediated transcription [44]. Since this is a central and common pathway of inflammation present in the airways of both asthma and COPD, this may signify a unifying underlying mechanism of both disease entities. Further studies are needed to confirm this hypothesis.

The strengths of our study are the data quality of the cohorts involved, the design of the study and the analysis strategy of the discovery and replication phases. There are some limitations to our study as well. We found no overall replication in six out of eight replication cohorts. One explanation for the lack of replication might be the differences in asthma and COPD patients in the replication cohorts compared with the identification cohort. For instance there was a somewhat lower prevalence of asthma in LifeLines 2 (7.5\% versus $8.5 \%$ in LifeLines 1 ) due to the average increased age of the subjects included in LifeLines 2. This could reflect a cohort effect or some asthma remission for the elder ages [45]. Furthermore, most studies used an asthma definition of self-reported asthma diagnosis. Self-reported asthma has led to firm GWAS findings in the GABRIEL study (a multidisciplinary study to identify the genetic and environmental causes of asthma in the European community) [46]. However, it cannot be excluded that our asthmatic 
groups consisted in part of individuals diagnosed with asthma in childhood, who now are in complete remission. The GABRIEL cohort studies suggested that the genetic background of early-onset and adultonset asthma is different. It would be of interest to assess whether COPD would have more overlap in genetic background with either childhood-onset than adult-onset asthma. A previous study from our group [47] showed overlap between candidate genes for COPD and early childhood wheeze and lower lung function, suggesting there is some overlap in genetic background in early childhood characteristics. This clearly needs further study, since we could not analyse this adequately in our cohort, where the prevalence of childhood asthma was $82 \%$ in our identification cohort and 41 in the verification cohort. Similarly, the diagnosis of COPD was based on lung function only, and this could have led to inclusion of different types of COPD in the various replication cohorts. For instance the prevalence of neversmokers was $41 \%$ in SAPALDIA, whereas this was $0 \%$ in the identification and LifeLines 1 and 2 cohorts and ranged from $10 \%$ to $24 \%$ in the other cohorts. Furthermore some cohorts were consisted of subjects that were of an increased age (e.g. mean age $\sim 65$ years in RS-I and RS-II and this may have led to inclusion of elderly asthmatics in the COPD group, since significant persistent airway-obstruction may occur in asthma with increase in age [48]. This may reflect an important limitation common to most GWAS, i.e. the heterogeneity of the phenotypes assessed and heterogeneity between discovery and replication samples. Table S3 shows the heterogeneity per meta-analysis performed, i.e. for each asthmaCOPD meta-analysis. It differs substantially and due to specificity of the study we could not account for the heterogeneity between meta-analyses. We did not find as prime hits a gene that was associated with asthma and with COPD previously. For instance ADAM33 was not significantly associated with either asthma or COPD or represented in their overlap. This may either be due to the fact that not all SNPs were captured in the GWAS analyses, or that ADAM33 was only found by positional cloning when hyperresponsiveness was present in asthmatics [49]. The latter was not a prerequisite in our asthma definition, just as in other GWAS studies, where ADAM33 was also not found as a significant gene associated with asthma.

Do our findings then refute the Dutch hypothesis? This hypothesis states that both genetic and environmental factors contribute to the phenotypic outcome and that there is a common genetic background. Indeed the current study did not find significant genetic similarities between asthma and COPD, apart from the identification cohort and LifeLines 1 . As highlighted by the Dutch hypothesis the importance of both type and temporal sequences of environmental exposures contribute to the occurrence of either phenotype. This may have affected the phenotypic outcome considerably and, hence, a crude covariate adjustment may represent an underestimated challenge to identify common genetic determinants of asthma and COPD. Finally, our study has power to identify strongly prevalent SNPs, yet not rare variants that may have an impact on asthma and COPD. Our findings either suggest that there is no common genetic component in asthma and COPD or, alternatively, different environmental factors, like lifestyle and occupation in different countries and continents may have obscured the genetic common contribution.

Recent efforts to characterise the substantial number of patients diagnosed with both asthma and COPD [50] show the increasing scientific interest in the phenotypic overlap between asthma and COPD. Future studies on the underlying genetics in this group of overlap patients would be of interest, specifically comparing outcomes with our results.

Overall, our results may suggest a role of the NF- $\kappa \beta$ pathway, a key transcription factor in the inflammatory response, in both asthma and COPD, suggesting that the Dutch hypothesis may have some validity. However, we could not replicate associations in both asthma and COPD in most replication cohorts, thus this could refute the genetic background that the Dutch hypothesis implied to be common in asthma and COPD. Further studies including lifelong lifestyle factors across all cohorts need to be performed to assess whether this approach elucidates a common genetic background of asthma and COPD. Since none of the SNPs reached genome-wide significance further investigation of the loci should be performed to assess their role in both asthma and COPD. Although inflammatory processes differ in asthma and COPD, they are unequivocally mediated by NF- $\kappa \beta$, and as suggested by our current results, they could be driven by the same underlying genes, COMMD10 and DDX1. Our eQTL studies support a functional role of COMMD10, since we established that two SNPs, therefore, the natural next step is to perform genome-wide epistatic analysis in large cohorts of asthma and COPD patients to reveal the complex nature of interactions between SNPs and loci and their impact on the ultimate phenotype.

\section{Acknowledgements}

The authors thank the staff and participants from the following studies for their important contributions: NELSON, DAG, LifeLines. SAPALDIA, Rotterdam Study, MESA and ARIC. 
NELSON: the authors thank H. de Koning, M. Oudkerk and W. Mali for their efforts in patient and data collection.

DAG: Patients participated from the Groningen cohorts (D.S. Postma and G.H. Koppelman), SiTA study (R. Riemersma and T. van der Molen), SGO asthma (E.F. Knol, C. Bruynzeel-Koomen, C.R. Gerth van Wijk and J.G.R. de Monchy), Prevasc (O. van Schayck), ELON (M. Kerkhof) and the Van Lookeren cohort (J. Vonk).

LifeLines cohort study: Expanded Banner or group author: Behrooz Z. Alizadeh, H. Marike Boezen, Harold Snieder, Ronald P. Stolk (Dept of Epidemiology, University of Croningen, Groningen, The Netherlands), Rudolf A. de Boer, Pim van der Harst (Dept of Cardiology, University of Groningen, The Netherlands), Hans L. Hillege (Depts of Epidemiology and Cardiology, University of Croningen, Groningen and The Netherlands) Marcel Bruinenberg (LifeLines cohort study, University of Groningen, University Medical Center Groningen, The Netherlands), Lude Franke and Cisca Wijmenga (Dept of Genetics, University of Groningen, University Medical Center Groningen, The Netherlands), Melanie M. van der Klauw and Bruce H.R. Wolffenbuttel (Dept of Endocrinology, University of Groningen, University Medical Center Groningen, The Netherlands), Gerjan Navis (Dept of Internal Medicine, Division of Nephrology, University Groningen, University Medical Center Groningen, The Netherlands) Johan Ormel and Judith G.M. Rosmalen (Interdisciplinary Center of Psychopathology of Emotion Regulation (ICPE) and Dept of Psychiatry, University of Groningen, University Medical Center Groningen, The Netherlands), Dirkje S. Postma (Dept of Pulmonology, University of Groningen, University Medical Center Groningen, GRIAC research institute, The Netherlands), Joris P. Slaets (University Center for Geriatric Medicine, University of Groningen, University Medical Center Groningen, The Netherlands). The authors also thank Behrooz Alizadeh, Annemieke Boesjes, Marcel Bruinenberg, Noortje Festen, Pim van der Harst, Ilja Nolte, Lude Franke and Mitra Valimohammadi for their help in creating the GWAS database. And Rob Bieringa, Joost Keers, René Oostergo, Rosalie Visser and Judith Vonk for their work related to data collection and validation. The authors are grateful to the study participants, the staff from the LifeLines cohort study and Medical Biobank Northern Netherlands, and the participating general practitioners and pharmacists.

SAPALDIA: The study could not have been done without the help of the study participants, technical and administrative support as well as the medical teams and field workers at the local study sites. Local fieldworkers include the following, place in city order. Aarau: M. Broglie, M. Bünter, D. Gashi; Basel: R. Armbruster, T. Damm, U. Egermann, M. Gut, L. Maier, A. Vögelin, L. Walter; Davos: D. Jud, N. Lutz; Geneva: M. Ares, M. Bennour, B. Galobardes, E. Namer, Lugano: B. Baumberger, S. Boccia Soldati, E. Gehrig-Van Essen, S. Ronchetto; Montana: C. Bonvin, C. Burrus; Payerne: S. Blanc, A.V. Ebinger, M.L. Fragnière, J. Jordan, Wald: R. Gimmi, N. Kourkoulos, U. Schafroth. The administrative staff: N. Bauer, D. Baehler, C. Gabriel, R. Gutknecht. The SAPALDIA team includes the study directorate T. Rochat, N.M. Probst Hensch, N. Künzli, C. Schindler and J.M. Gaspoz; the scientific team: J.C. Barthélémy, W. Berger, R. Bettschart, A. Bircher, G. Bolognini, O. Brändli, C. Brombach, M. Brutsche, L. Burdet, M. Frey, U. Frey, M.W. Gerbase, D. Gold, E. de Groot, W. Karrer, R. Keller, B. Knöpfli, B. Martin, D. Miedinger, U. Neu, L. Nicod, M. Pons, F. Roche, T. Rothe, E. Russi, P. Schmid-Grendelmeyer, A. Schmidt-Trucksäss, A. Turk, J. Schwartz, D. Stolz, P. Straehl, J.M. Tschopp, A. von Eckardstein and E. Zemp Stutz; and the scientific team at coordinating centres: M. Adam, E. Boes, P.O. Bridevaux, D. Carballo, E. Corradi, I. Curjuric, J. Dratva, A. Di Pasquale, L. Grize, D. Keidel, S. Kriemler, A. Kumar, M. Imboden, N. Maire, A. Mehta, F. Meier, H. Phuleria, E. Schaffner, G.A. Thun, A. Ineichen, M. Ragettli, M. Ritter, T. Schikowski, G. Stern, M. Tarantino, M. Tsai and M. Wanner.

The Lung eQTL Consortium: The lung specimens from the Laval University group were collected at the Institut universitaire de cardiologie et de pneumologie de Québec (IUCPQ) site of the Respiratory Health Network Tissue Bank of the Fonds de recherche du Québec - Santé (Quebec, Canada) (www.tissuebank.ca).The authors would like to thank the research staff at the tissue bank for their valuable assistance. Yohan Bossé is a research scholar from the Heart and Stroke Foundation of Canada.

The Rotterdam Study: We thank Pascal Arp, Mila Jhamai, Marijn Verkerk, Lizbeth Herrera and Marjolein Peters for their help in creating the GWAS database, and Karol Estrada and Maksim V. Struchalin for their support in creation and analysis of imputed data. The authors are grateful to the study participants, the staff from the Rotterdam Study and the participating general practitioners and pharmacists.

MESA: The authors thank the participants of the MESA study, the coordinating centre, MESA investigators, and study staff for their valuable contributions. A full list of participating MESA investigators and institutions can be found at http://www.mesa-nhlbi.org.

\section{References}

1 Masoli M, Fabian D, Holt S, et al. The global burden of asthma: executive summary of the GINA Dissemination Committee report. Allergy 2004; 59: 469-478.

Masoli M, Fabian D, Holt S, et al. Global Burden of Asthma. Global Initiative for Asthma (GINA), 2004.

3 Halbert RJ, Isonaka S, George D, et al. Interpreting COPD prevalence estimates: what is the true burden of disease? Chest 2003; 123: 1684-1692.

4 Kraft M. Asthma and chronic obstructive pulmonary disease exhibit common origins in any country! Am J Respir Crit Care Med 2006; 174: 238-240.

Plusa T. Zespół "nakładania" astmy i przewlekłej obturacyjnej choroby płuc [Overlap syndrome-asthma and chronic obstructive pulmonary disease]. Pneumonol Alergol Pol 2011; 79: 351-356.

Monteseirin J. Neutrophils and asthma. J Investig Allergol Clin Immunol 2009; 19: 340-354.

Papi A, Bellettato CM, Braccioni F, et al. Infections and airway inflammation in chronic obstructive pulmonary disease severe exacerbations. Am J Respir Crit Care Med 2006; 173: 1114-1121.

8 Orie N, Sluiter H, DeVries K, et al. The host factor in bronchitis. In: Bronchitis; an International Symposium, 27-29 April 1960, Gronigen. Assen, Royal Van Gorcum, 1961; pp. 43-59.

9 Barnes PJ. Against the Dutch hypothesis: asthma and chronic obstructive pulmonary disease are distinct diseases. Am J Respir Crit Care Med 2006; 174: 240-243.

10 Postma DS, Kerkhof M, Boezen HM, et al. Asthma and chronic obstructive pulmonary disease: common genes, common environments? Am J Respir Crit Care Med 2011; 183: 1588-1594. 
11 Postma DS, Bleecker ER, Amelung PJ, et al. Genetic susceptibility to asthma-bronchial hyperresponsiveness coinherited with a major gene for atopy. N Engl J Med 1995; 333: 894-900.

12 A genome-wide search for asthma susceptibility loci in ethnically diverse populations. The Collaborative Study on the Genetics of Asthma (CSGA). Nat Genet 1997; 15: 389-392.

$13 \mathrm{Xu}$ J, Meyers DA, Ober C, et al. Genomewide screen and identification of gene-gene interactions for asthmasusceptibility loci in three U.S. populations: collaborative study on the genetics of asthma. Am J Hum Genet 2001; 68: 1437-1446.

14 Silverman EK, Palmer LJ, Mosley JD, et al. Genomewide linkage analysis of quantitative spirometric phenotypes in severe early-onset chronic obstructive pulmonary disease. Am J Hum Genet 2002; 70: 1229-1239.

15 Palmer LJ, Celedon JC, Chapman HA, et al. Genome-wide linkage analysis of bronchodilator responsiveness and post-bronchodilator spirometric phenotypes in chronic obstructive pulmonary disease. Hum Mol Genet 2003; 12: 1199-1210.

16 Nicolaides NC, Holroyd KJ, Ewart SL, et al. Interleukin 9: a candidate gene for asthma. Proc Natl Acad Sci USA 1997; 94: 13175-13180.

17 Duetsch G, Illig T, Loesgen S, et al. STAT6 as an asthma candidate gene: polymorphism-screening, association and haplotype analysis in a Caucasian sib-pair study. Hum Mol Genet 2002; 11: 613-621.

18 Nicolae D, Cox NJ, Lester LA, et al. Fine mapping and positional candidate studies identify HLA-G as an asthma susceptibility gene on chromosome 6p21. Am J Hum Genet 2005; 76: 349-357.

19 Castaldi PJ, Cho MH, Cohn M, et al. The COPD genetic association compendium: a comprehensive online database of COPD genetic associations. Hum Mol Genet 2010; 19: 526-534.

20 Zhang Y, Moffatt MF, Cookson WO. Genetic and genomic approaches to asthma: new insights for the origins. Curr Opin Pulm Med 2012; 18: 6-13.

21 Wain LV, Artigas MS, Tobin MD What can genetics tell us about the cause of fixed airflow obstruction? Clin Exp Allergy 2012; 42: 1176-1182.

22 Smolonska J, Wijmenga C, Postma DS, et al. Meta-analyses on suspected chronic obstructive pulmonary disease genes: a summary of 20 years' research. Am J Respir Crit Care Med 2009; 180: 618-631.

23 Himes BE, Klanderman B, Ziniti J, et al. Association of SERPINE2 with asthma. Chest 2011; 140: 667-674.

24 Van Eerdewegh P, Little RD, Dupuis J, et al. Association of the ADAM33 gene with asthma and bronchial hyperresponsiveness. Nature 2002; 418: 426-430.

25 van Diemen CC, Postma DS, Vonk JM, et al. A disintegrin and metalloprotease 33 polymorphisms and lung function decline in the general population. Am J Respir Crit Care Med 2005; 172: 329-333.

26 Jongepier H, Boezen HM, Dijkstra A, et al. Polymorphisms of the ADAM33 gene are associated with accelerated lung function decline in asthma. Clin Exp Allergy 2004; 34: 757-760.

27 Vink NM, Postma DS, Nieuwenhuis MA, et al. No associations of the mineralocorticoid and glucocorticoid receptor genes with asthma. Eur Respir J 2012; 40: 1572-1574.

28 van Iersel CA, de Koning HJ, Draisma G, et al. Risk-based selection from the general population in a screening trial: selection criteria, recruitment and power for the Dutch-Belgian randomised lung cancer multi-slice CT screening trial (NELSON). Int J Cancer 2007; 120: 868-874.

29 Fehrmann RS, Jansen RC, Veldink JH, et al. Trans-eQTLs reveal that independent genetic variants associated with a complex phenotype converge on intermediate genes, with a major role for the HLA. PLoS Genet 2011; 7: e1002197.

30 Hao K, Bosse Y, Nickle DC, et al. Lung eQTLs to help reveal the molecular underpinnings of asthma. PLoS Genet 2012; 8: e1003029.

31 Irizarry RA, Hobbs B, Collin F, et al. Exploration, normalization, and summaries of high density oligonucleotide array probe level data. Biostatistics 2003; 4: 249-264.

32 Schadt EE, Molony C, Chudin E, et al. Mapping the genetic architecture of gene expression in human liver. PLoS Biol 2008; 6: e107.

33 Mostafavi S, Ray D, Warde-Farley D, et al. GeneMANIA: a real-time multiple association network integration algorithm for predicting gene function. Genome Biol 2008; 9: Suppl. 1, S4.

34 Chang JT, Nevins JR GATHER. a systems approach to interpreting genomic signatures. Bioinformatics 2006; 22: 2926-2933.

35 Lee J, Sandford A, Man P, et al. Is the aging process accelerated in chronic obstructive pulmonary disease? Curr Opin Pulm Med 2011; 17: 90-97.

36 Kong X, Cho MH, Anderson W, et al. Genome-wide association study identifies BICD1 as a susceptibility gene for emphysema. Am J Respir Crit Care Med 2011; 183: 43-49.

37 Soler AM, Loth DW, Wain LV, et al. Genome-wide association and large-scale follow up identifies 16 new loci influencing lung function. Nat Genet 2011; 43: 1082-1090.

38 Burstein E, Hoberg JE, Wilkinson AS, et al. COMMD proteins, a novel family of structural and functional homologs of MURR1. J Biol Chem 2005; 280: 22222-22232.

39 de Bie P, van de Sluis B, Klomp L, et al. The many faces of the copper metabolism protein MURR1/COMMD1. J Hered 2005; 96: 803-811.

40 Handy RD, Eddy FB, Baines H. Sodium-dependent copper uptake across epithelia: a review of rationale with experimental evidence from gill and intestine. Biochim Biophys Acta 2002; 1566: 104-115.

41 Eaton DC, Helms MN, Koval M, et al. The contribution of epithelial sodium channels to alveolar function in health and disease. Annu Rev Physiol 2009; 71: 403-423.

42 Poliseno L, Salmena L, Zhang J, et al. A coding-independent function of gene and pseudogene mRNAs regulates tumour biology. Nature 2010; 465: 1033-1038.

43 Postma DS, Koppelman GH Confirmation of GPRA. a putative drug target for asthma. Am J Respir Crit Care Med 2005; 171: 1323-1324

44 Ishaq M, Ma L, Wu X, et al. The DEAD-box RNA helicase DDX1 interacts with RelA and enhances nuclear factor kappaB-mediated transcription. J Cell Biochem 2009; 106: 296-305.

45 Vonk JM, Postma DS, Boezen HM, et al. Childhood factors associated with asthma remission after 30 year follow up. Thorax 2004; 59: 925-929.

46 Moffatt MF, Gut IG, Demenais F, et al. A large-scale, consortium-based genomewide association study of asthma. N Engl J Med 2010; 363: 1211-1221. 
47 Van Eerdewegh P, Little RD, Dupuis J, et al. Association of the ADAM33 gene with asthma and bronchial hyperresponsiveness. Nature 2002; 418: 426-430.

48 Vonk JM, Jongepier H, Panhuysen CI, et al. Risk factors associated with the presence of irreversible airflow limitation and reduced transfer coefficient in patients with asthma after 26 years of follow up. Thorax 2003; 58: 322-327.

49 Kerkhof M, Boezen HM, Granell R, et al. Transient early wheeze and lung function in early childhood associated with chronic obstructive pulmonary disease genes. J Allergy Clin Immunol 2014; 133: 68-76.

50 Hardin M, Silverman EK, Barr RG, et al. The clinical features of the overlap between COPD and asthma. Respir Res 2011; 12: 127. 